\section{Saree cancer in Indian woman treated successfully with multimodality management}

\author{
Unmesh Vidyadhar Takalkar, ${ }^{1}$ \\ Shilpa Balaji Asegaonkar, ${ }^{2}$ \\ Pushpa Kodlikeri, ${ }^{1}$ Ujwala Kulkarni, ${ }^{1}$ \\ Virendrakumar Borundiya, ${ }^{1}$ \\ Suresh H. Advani ${ }^{3}$ \\ 'United CIIGMA Hospital, Aurangabad; \\ ${ }^{2}$ Government Medical College, \\ Aurangabad; ${ }^{3}$ Asian Institute of \\ Oncology, SL Raheja Hospital, Mumbai, \\ India
}

\begin{abstract}
Saree is a common, traditional garment of Indian women, wrapped around the waist is tightened by a thick cord and with one end draped over the shoulder. Tight knot in the same place, sweat, soiling and continuous use can cause pigmentation, scaling of the waist and even transform to malignancy. We present here a case of saree cancer successfully managed with multimodality therapy. A 50-year-old woman was referred to our hospital (India) for itching and non-healing ulcerative lesion on waistline. She was wearing saree continuously for 34 years with knot at the same place. Magnetic resonance images suggested ulcerative growth with lymph node metastasis. She then underwent wide local excision; histopathological examination confirmed it was a squamous cell carcinoma. She therefore received concomitant chemotherapy and radiotherapy. She is now (2 years after the completion of treatment) in remission state. Awareness of saree cancer among Indian is important to avoid malignant lesions at waistline. Multimodality management with surgery, chemotherapy and radiotherapy is ideal mean for good outcome.
\end{abstract}

\section{Introduction}

The saree is a common, traditional and popular attire of Indian women. It is a strip of unstitched cloth with four to nine yards of various fabric materials, which can be worn in different styles. It is draped around waist over inner skirt (petticoat) which is tightened by a thick cord. Most of Indian women wear saree life time throughout the day and night in hot and humid climate. Tight knot on waist at the same place, perspiration, sweat, soiling and long term use results in pigmentation scaling of the waist. These changes may transform to malignant changes at the waistline rarely. ${ }^{1}$

Previously, just a few cases regarding saree cancers detected among Indian women have been reported in literature, but all these cases were managed by surgical excision with course of antibiotics. ${ }^{1-4}$ The authors herein present a case of saree cancer at waistline, which was successfully managed with multimodality therapy consisting of surgery, chemotherapy and radiotherapy.

\section{Case Report}

A 50 year old farmer woman from rural area was referred to our center (India) with chief complaint of itching and non-healing ulcerative lesion at the site of knot of petticoat at waistline since last two years. Previously she took treatment from local general practitioner, but symptoms did not relieved and lesion progressed with watery discharge turned to pus. On acquisition of detail clinical history, we found that she was married at the age of 16 and was wearing for 34 years saree with knot at same place. The lesion started initially as irritation, hyper pigmented and scaly small patch. Then gradually lesion increased in size with watery discharge. After applying ointments and completing course of antibiotics advised by local physician, lesion did not subsided and hence referred to our center. Her past medical and surgical history was unremarkable. She was not suffering from diabetes mellitus, hypertension, cardiovascular disease and any other major illness.

Clinical examination revealed a non-healing ulcer (Figure 1) on left side of waistline measuring $6 \times 3 \mathrm{~cm}$ with everted edges, rolled up margins and serosangious discharge from the thick indurate ulcer bed. On palpation ulcer was firm, tender and bleed on touching, surrounding skin was hypo pigmented and scaly. Inguinal lymph nodes were palpable and tender. Laboratory investigations including hematological and biochemical parameters were within normal range. Wedge biopsy from the lesion showed presence of malignant cells suggestive of squamous cell carcinoma. Magnetic resonance image of pelvis showed (Figure 2) multiple conglomerate hyper intense lesions with air foci in subcutaneous plane in anterior abdominal wall in left iliac fossa region measuring $1.85 \times 5.3 \mathrm{~cm}$. Loss of fat planes with underlying abdominal wall muscle suggested possibility of muscle invasion without imaging signs of peritoneal extension. Few lymph nodes were enlarged in left inguinal region with largest measuring $10.6 \mathrm{~mm}$. These findings suggested evidence of ulcerative growth with muscle invasion and lymph node metastasis in left iliac fossa. To downstage the disease we first administered 2
Correspondence: Unmesh Vidyadhar Takalkar, United CIIGMA Hospital, Opposite Easy Day Mall, Shahanoor wadi, Garkheda, Aurangabad 431005, India.

Tel. +91.982.2042425.

E-mail: drunmesh.aurangabad@gmail.com

Key words: saree, cutaneous squamous cell carcinoma, concomitant radiotherapy, chemotherapy.

Contributions: the authors contributed equally.

Conflict of interests: the authors declare no potential conflict of interests.

Received for publication: 16 0ctober 2013.

Revision received: 7 January 2014.

Accepted for publication: 25 January 2014.

This work is licensed under a Creative Commons Attribution NonCommercial 3.0 License (CC BYNC 3.0).

(C) Copyright U.V. Takalkar et al., 2014

Licensee PAGEPress, Italy

Dermatology Reports 2014; 6:5128

doi:10.4081/dr.2014.5128

cycles of chemotherapy with paclitaxel and carboplatin before proceeding to surgical management. After thorough diagnostic work up and preoperative evaluation she underwent wide local excision $1 \mathrm{~cm}$ margin with primary skin grafting. Histopathological examination of the specimen confirmed diagnosis of squamous cell carcinoma with tumor free surgical margins moderately differentiated of grade II with $\mathrm{T}_{3} \mathrm{~N}_{1} \mathrm{M}_{0}$ stage III. Post operative period was uneventful. After recovery we proceeded with concomitant chemotherapy with cisplatin and radiotherapy. Our patient tolerated well this management throughout complete course without any adverse event. Now she in remission state for last 2 years from the completion of treatment.

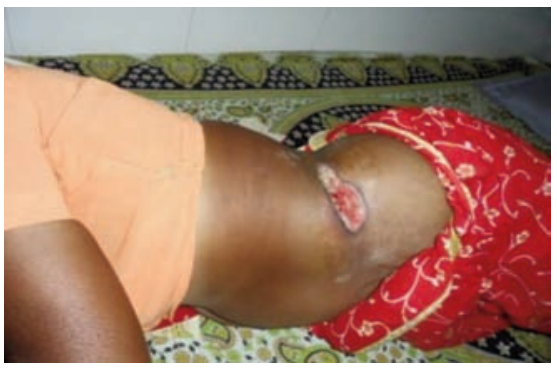

Figure 1. Picture showing malignant skin ulcer along waist line. 

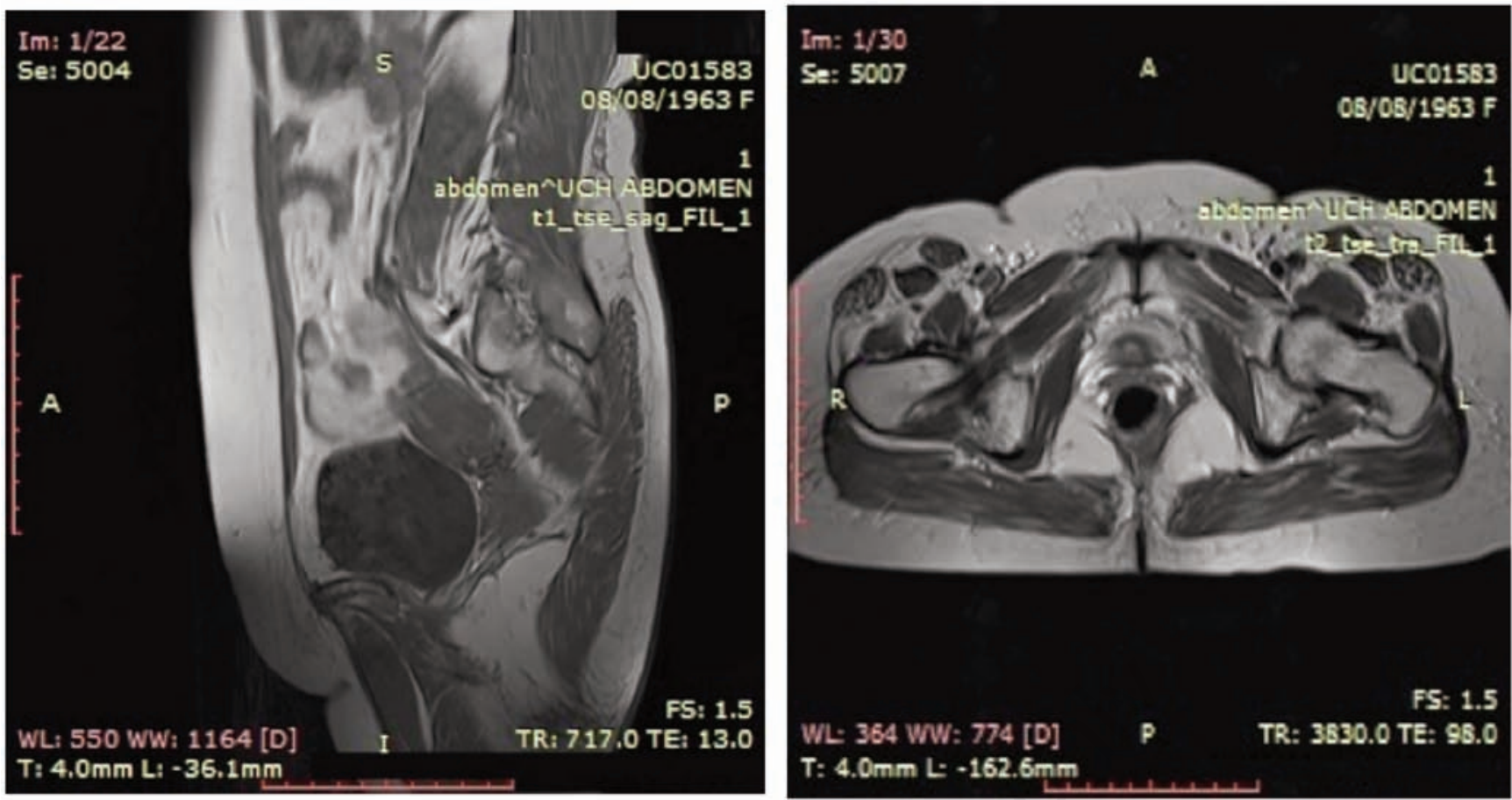

Figure 2. Magnetic resonance images of pelvis.

\section{Discussion}

The term of saree cancer among Indian women was first introduced by Patil et al. ${ }^{1}$ Saree is a famous traditional Indian costume. But with constant use for longer duration dermatological problems along the waistline have been recognized by the researchers. Eapen $e t$ $a l^{5}$ assessed prevalence and presentation of various dermatoses along the waist in 140 females wearing saree and observed hyper pigmentation and scaly skin changes. ${ }^{5}$ Cutaneous squamous cell carcinoma is developed in chronically diseased skin, long standing ulcers, radiation dermatitis, sinus tracts, osteomyelitis, scars and certain inflammatory disorders. If such lesions remain neglected and untreated for long duration, they transform into malignancy with high risk of metastasis. ${ }^{6}$ Squamous cell carcinomas developing from injured lesions or chronic long standing skin disease are at risk of metastasis by $40 \%{ }^{7}$

Prognosis of cutaneous squamous cell carcinoma depends on site and size of lesion, depth of invasion, histological characteristics and immune status of the patient. ${ }^{8}$ If detected in early stage results in favorable prognosis. Follow up is very important to detect recurrence or persistence of the tumor and presence of new lesion.

In the present case muscle invasion and lymph node metastasis were the adverse prognostic factors. But combination of surgery, chemotherapy and radiotherapy in the management of our case achieved loco regional control of the tumor. We recommend practice of multimodality treatment with concomitant chemoradiotherapy after wide surgical excision in high risk skin cancers. Administration of chemotherapy before surgical management decreases tumor load. Addition of chemotherapy for radio sensitization of the tumor improves outcome in patients with advanced disease.

Up till now four case reports have been described in literature among Indian women. But all cases were managed with surgical excision and course antibiotics. As our patient presented with metastasis to regional lymph nodes and invasion of muscle by tumor cells, we opted first chemotherapy followed by wide surgical excision and then concomitant radio chemotherapy. Hence our experience suggests that in case of more advanced cases of saree cancer, a combination of surgery, radiotherapy and chemotherapy may be of extra value compared to surgery alone.

\section{Conclusions}

Awareness about saree cancer due to continuous long term knot at the same place among Indian women is important to prevent waistline dermatoses and their progression to malignant lesions. Clinicians should offer best possible treatment of such lesions with multimodality approach.

\section{References}

1. Patil AS, Bakshi GD, Puri YS, et al. Saree cancer. Bombay Hosp J 2005;47:302-3.

2. Kamble AS, Gokhale S. Saree cancer: a case report. Int $\mathrm{J}$ Biol Med Res 2012;3:1540-1.

3. Bakshi GD, Borisa A, Tayade MB. Waist cancer: report of two cases. J Indian Med Assoc 2011;109:829-31.

4. Vagholkar KR. Cutaneous squamous cell carcinoma at an unusual site. Internet $\mathrm{J}$ Dermatol 2010. Available from: http://ispub.com/IJD/8/1/13208.

5. Eapen BR, Shabana S, Anandan S. Waist dermatoses in Indian women wearing saree. Indian J Dermatol Venerol Leprol 2003:69;88-9.

6. Alam M, Ratner D. Cutaneous squamouscell carcinoma. N Engl J Med 2001;344: 975-83.

7. Rowe DE, Carroll RJ, Day CL Jr. Prognostic factors for local recurrence, metastasis, and survival rates in squamous cell carcinoma of the skin, ear, and lip: implications for treatment modality selection. J Am Acad Dermatol 1992:26;976-90.

8. Motley RJ, Preston PW, Lawrence CM. Multi-professional Guidelines for the Management of the Patient with Primary Cutaneous Squamous Cell Carcinoma. Br J Dermatol 2002;146:18-25. 